\title{
ATIVIDADE IN VITRO DE COMPOSTOS DERIVADOS DE TIAZÓIS SOBRE MELANOMA MURINO
}

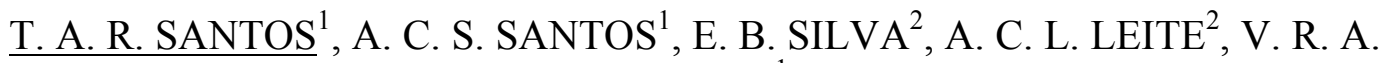 \\ PEREIRA $^{1}$
}

${ }^{1}$ Laboratório de Imunogenética, Departamento de Imunologia, Centro de Pesquisas Aggeu Magalhães.

${ }^{2}$ Laboratório de de Síntese de Fármacos, Departamento de Ciências Farmacêuticas, Universidade Federal de Pernambuco

E-mail para contato: tandre.ufpe@gmail.com

RESUMO - O câncer continua sendo uma das principais causas de morte em todo o mundo, com incidência anual de 8,2 milhões. A química medicinal tem contribuído desde a criação dos primeiros medicamentos desenvolvidos para o câncer, e continua trazendo novas alternativas e potenciais candidatos a fármacos antitumorais. O desenvolvimento de pequenas moléculas com atividade biológica é importante, pois proporciona novas alternativas ao tratamento do câncer. Neste trabalho, foram avaliados seis compostos tiazóis frente à linhagem tumoral B16F10 e esplenócitos murinos. Para isto, células da linhagem B16F10 e esplenócitos de camundongos BALB/c foram incubados com diversas concentrações dos compostos avaliados. Após a incubação, a atividade antitumoral foi determinada por ensaio com MTT. Já a citotoxicidade dos compostos sobre os esplenócitos foi verificada por ensaios utilizando timidina tritiada. Para ambos os tipos celulares foram determinados valores de $C_{50}$. Os compostos analisados causaram toxicidade variada tanto na linhagem tumoral, como nos esplenócitos. O composto AT2 mostrou-se mais ativo para a linhagem B16F10, sendo quase 3 vezes mais tóxico para esta que para os esplenócitos.

Palavras-chave: tiazóis; linhagem B16F10; atividade antitumoral.

\begin{abstract}
Cancer remains one of the main causes of death worldwide with an annual incidence of 8.2 million. Medicinal chemistry has contributed since the creation of the first drugs developed for cancer, and continues to bring new alternatives and potential candidates for antitumor drugs. The development of small molecules with biological activity is important once it provides new alternatives for cancer treatment. In this work, six thiazole compounds were evaluated against the B16F10 tumor line and murine splenocytes. For this, B16F10 cells and splenocytes from BALB / c mice were incubated with various concentrations of compounds. After incubation, antitumor activity was determined by MTT assay. On the other hand, cytotoxicity of compounds on splenocytes was verified by tritiated thymidine assay. For both cell types $C_{50}$ values were determined. The compounds analyzed caused varied toxicity in tumor line and in
\end{abstract}


splenocytes. Compound AT2 was more active for B16F10, and nearly 3 times more toxic for this as for the splenocytes.

Keywords: thiazoles; B16F10 cell line; antitumor activity.

\section{INTRODUÇÃO}

O câncer continua sendo uma das principais causas de morte em todo o mundo, tendo sido a causa de 8,2 milhões de mortes em 2012 (FERLAY et al., 2013). Essa patologia surge de um processo mutagênico que ocorre em múltiplas etapas, no qual as células cancerosas adquirem um conjunto comum de propriedades incluindo potencial de proliferação ilimitado, auto-suficiência em sinais de crescimento, e resistência a sinais anti-proliferativos e de apoptose (LUO; SOLIMINI; ELLEDGE, 2009).

Mesmo com grandes esforços por parte de órgãos públicos e privados, o caráter generalizado, severo e muitas vezes letal do câncer persiste, com apenas melhorias elementares no tratamento (KAMB; WEE; LENGAUER, 2007).

A química medicinal contribuiu na descoberta dos primeiros medicamentos desenvolvidos para o câncer, e continua uma abordagem atual no desenvolvimento de novas alternativas e potenciais candidatos a fármacos antitumorais.

Dentro dessa perspectiva, diversos grupamentos químicos chamam a atenção pelo amplo espectro de atividades biológicas associados, além da verificação de efeitos imunomodulatórios. Os tiazóis são frequentemente encontrados em vários compostos com potente atividade biológica, como sulfatiazol (antimicrobiano), Ritonavir (antiviral), além de ser um motivo estrutural comumente encontrado em agentes anticâncer, como bleomicina, tiazofurina e desatinib (KASHYAP et al., 2011; SCHADE et al., 2008; ZHENG et al., 2013). São potenciais compostos base para a criação de novas moléculas biologicamente ativas, mesmo que suas atividades biológicas incluam efeitos favoráveis e desfavoráveis (HASHIMOTO, 2008). O desenvolvimento de pequenas moléculas com atividade biológica, além do aprimoramento de outros meios de tratamento, é importante, pois proporciona novas alternativas ao tratamento do câncer.

Neste trabalho, 6 compostos contendo em suas estruturas o grupamento tiazol foram avaliados quanto a sua atividade citotóxica sobre células saudáveis (esplenócitos) e quanto a sua ação anticâncer sobre células da linhagem de melanoma murino B16F10.

\section{MATERIAIS E MÉTODOS}

\subsection{Compostos}

Os compostos foram obtidos em colaboração com o Laboratório de Planejamento em Química Medicinal (LPQM) do Departamento de Farmácia da UFPE. Foram inicialmente solubilizados em DMSO e posteriormente diluídos em meio de cultura para a realização dos ensaios.

\subsection{Células}

Neste trabalho foram utilizados esplenócitos, obtidos de camundongos BALB/c machos (SANTIAGO et al., 2014). Os esplenócitos foram mantidos em meio RPMI 1640 suplementado com $10 \%$ de soro fetal bovino (SFB). O protocolo de experimentação animal utilizado no presente trabalho foi aprovado pela Comissão de Ética no Uso de Animais (CEUA) da FIOCRUZ com registro 26/2011. A linhagem B16F10 é derivada 
de um melanoma de Mus musculus, cepa C57BL6/6J. Estas células foram cultivadas aderidas em garrafas T25 contendo meio DMEM, suplementado com 10\% de SFB. Ambas as culturas foram mantidas a $37^{\circ} \mathrm{C}$ em estufa com $5 \%$ de $\mathrm{CO}_{2}$.

\subsection{Ensaio de atividade antitumoral}

A atividade antitumoral dos compostos sobre as células B16F10 foi realizado por MTT (brometo de [3-(4,5-dimetiltiazol-2-il)-2,5-difeniltetrazólio]). As células foram incubadas em placas de cultura de 96 poços em estufa a $5 \%$ de $\mathrm{CO}_{2}, 37^{\circ} \mathrm{C}, 24 \mathrm{~h}$. Diferentes concentrações dos compostos $(100,50,25,10,5$ e $1 \mu \mathrm{g} / \mathrm{ml})$ foram adicionadas, sendo incubadas durante $72 \mathrm{~h}$. Também foram utilizados poços controles sem adição de compostos. Após esse período, foi adicionado MTT ( $5 \mathrm{mg} / \mathrm{mL}$, em PBS), incubando-se por $2 \mathrm{~h}$, sendo acrescentado DMSO para a dissolução dos cristais formazan. A leitura da absorbância foi realizada a 540nm e a $\mathrm{CC}_{50 \mathrm{~B} 16 \mathrm{~F} 10}$ foi determinada. Os valores de $\mathrm{CC}_{50}$ foram determinados por análise de regressão pelo software GraphPad Prism.

\subsection{Ensaio de citotocixidade sobre esplenócitos murinos}

Os esplenócitos foram incubados com os compostos $(100,50,25,10,5$ e $1 \mu \mathrm{g} / \mathrm{ml})$, ou com meio de cultura apenas e com timidina tritiada (3H-timidina) $(1 \mu \mathrm{Ci} /$ poço) durante $24 \mathrm{~h}$ em estufa de $\mathrm{CO}_{2}$ a $37^{\circ} \mathrm{C}$. Após a incubação foi realizada coleta em papel de fibra de vidro e a incorporação de timidina tritiada pelas células foi determinada através de contador beta de cintilação. A partir da inibição da proliferação dos esplenócitos, comparando-se ao controle sem tratamento, foi determinada a $\mathrm{CC}_{50 \mathrm{ESP}}$, também por análise de regressão utilizando o software GraphPad Prism.

\section{RESULTADOS E DISCUSSÃO}

A figura 1 mostra a estrutura dos compostos e seus radicais substituintes. Os resultados de $\mathrm{CC}_{50}$ variaram bastante entre os compostos analisados, para ambos os tipos de células utilizados. Os valores de $\mathrm{CC}_{50 \mathrm{ESP}}$ variaram entre 19,21 $\mu \mathrm{M}$ e 51,77 $\mu \mathrm{M}$ (Tabela 1). O composto AT1, que constitui a molécula original, não substituída, apresentou-se como o mais tóxico para esplenócitos, com o menor valor de $\mathrm{CC}_{50 \mathrm{ESP}}$, de 19,21 $\mu \mathrm{M}$. Já o composto AT2, que possui substituição por $\mathrm{NO}_{2}$, foi o que apresentou menor toxicidade sobre os esplenócitos, com valor de $\mathrm{CC}_{50 \mathrm{ESP}}$ de $51,77 \mu \mathrm{M}$. Nos ensaios com a linhagem tumoral B16F10 também foi observada variações quanto à atividade dos compostos. Os valores variaram entre $18,55 \mu \mathrm{M}$ e $52,74 \mu \mathrm{M}$ (Tabela 1). O composto AT6, com substituição por bromo, foi o que se apresentou menos efetivo contra as células tumorais, com valor de $\mathrm{CC}_{50 \mathrm{~B} 16 \mathrm{~F} 10}$ de $52,74 \mu \mathrm{M}$. Já o composto $\mathrm{AT} 2$, que possui $\mathrm{NO}_{2}$ em sua substituição, pode ser considerado o mais efetivo, pois seu valor de $\mathrm{CC}_{50 \mathrm{~B} 16 \mathrm{~F} 10}$, de 18,55 $\mu \mathrm{M}$, foi menor que o apresentado para os esplenócitos. AT2 também se mostrou mais seletivo para células tumorais em relação aos esplenócitos, sendo quase 3 vezes mais ativo sobre a linhagem $\mathrm{B} 16 \mathrm{~F} 10$. Um menor valor de $\mathrm{CC}_{50}$ para a linhagem tumoral que para células saudáveis é desejável, visto que pode refletir numa menor toxicidade para modelos in vivo (HAMBLEY, 2009). 
Figura 1- Estrutura básica dos compostos suas substituições.

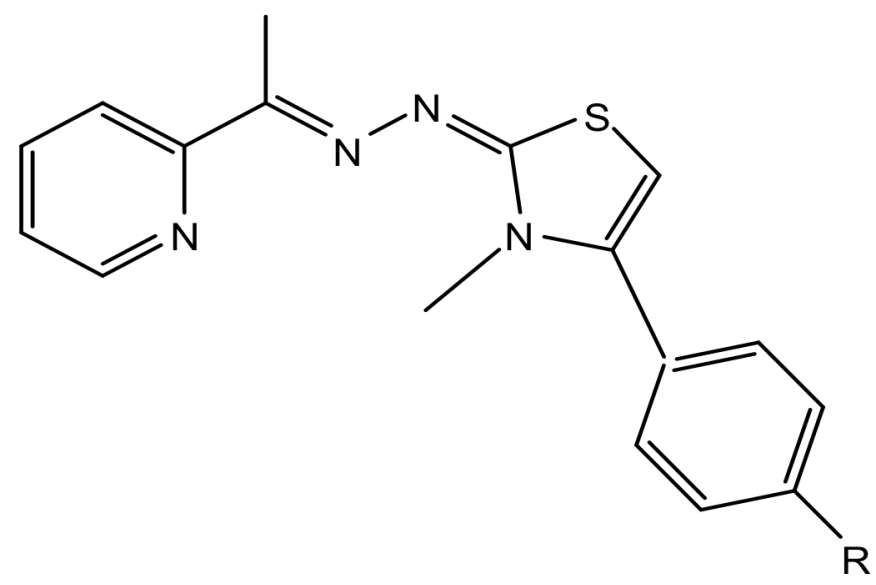

\begin{tabular}{|cc|}
\hline Composto & $\mathbf{R}$ \\
\hline AT-01 & H \\
\hline AT-02 & NO $_{2}$ \\
\hline AT-03 & OMe \\
\hline AT-04 & $\mathbf{C l}$ \\
\hline AT-06 & Br \\
\hline AT-09 & F \\
\hline
\end{tabular}

Tabela 1 - Valores de $\mathrm{CC}_{50}$ dos compostos sobre esplenócitos murinos e sobre a linhagem tumoral B16F10

\begin{tabular}{ccc}
\hline Compostos & $\begin{array}{c}\mathbf{C C}_{\mathbf{5 0 E S P}} \\
(\boldsymbol{\mu M})\end{array}$ & $\begin{array}{c}\mathbf{C C}_{\mathbf{5 0 B 1 6 F 1 0}} \\
(\boldsymbol{\mu M})\end{array}$ \\
\hline AT1 & 19,21 & 19,94 \\
AT2 & 51,77 & 18,55 \\
AT3 & 21,33 & 49,54 \\
AT4 & 28,29 & 25,73 \\
AT6 & 37,55 & 52,74 \\
AT9 & 34,87 & 19,03 \\
\hline
\end{tabular}

\section{CONCLUSÃO}

Os compostos avaliados apresentaram toxicidade variada sobre células esplênicas e sobre a linhagem tumoral B16F10;

O composto AT2 apresentou boa atividade antitumoral, com menor valor de $\mathrm{CC}_{50}$ para a linhagem tumoral testada que para as células esplênicas, refletindo uma maior seletividade para as células tumorais, que poderia acarretar numa possível menor toxicidade para modelos in vivo.

\section{REFERÊNCIAS}

FERLAY, J. et al. GLOBOCAN 2012 v1.0, Cancer Incidence and Mortality Worldwide: IARC CancerBase No. 11 [Internet]. International Agency for Research on Cance, v. 1.0, n. Cancer Incidence and Mortality Worldwide: IARC CancerBase No. 11 [Internet], 2013.

HAMBLEY, T. W. Is anticancer drug development heading in the right direction? Cancer research, v. 69, n. 4, p. 1259-62, fev. 2009.

HASHIMOTO, Y. Thalidomide as a multi-template for development of biologically active compounds. Archiv der Pharmazie, v. 341, n. 9, p. 536-47, set. 2008. 
KAMB, A.; WEE, S.; LENGAUER, C. Why is cancer drug discovery so difficult? Nature Reviews Drug Discovery, v. 6, n. 2, p. 115-120, 8 fev. 2007.

KASHYAP, S. J. et al. Thiazoles: having diverse biological activities. Medicinal Chemistry Research, v. 21, n. 8, p. 2123-2132, 28 jun. 2011.

LUO, J.; SOLIMINI, N. L.; ELLEDGE, S. J. Principles of cancer therapy: oncogene and non-oncogene addiction. Cell, v. 136, n. 5, p. 823-37, mar. 2009.

SANTIAGO, E. D. F. et al. Evaluation of the Anti- Schistosoma mansoni Activity of Thiosemicarbazones and Thiazoles. v. 58, n. 1, p. 352-363, 2014.

SCHADE, A. E. et al. Dasatinib, a small-molecule protein tyrosine kinase inhibitor, inhibits T-cell activation and proliferation. Blood, v. 111, n. 3, p. 1366-77, 1 fev. 2008.

ZHENG, S. et al. Discovery of a Series of Thiazole Derivatives as Novel Inhibitors of Metastatic Cancer Cell Migration and Invasion. ACS medicinal chemistry letters, v. 4, n. 2, p. 191-196, 14 fev. 2013.

\section{AGRADECIMENTOS}

Agradecimentos à FACEPE e CNPq pela disponibilização de recursos e à FIOCRUZ-PE pela infraestrutura fornecida. 